\title{
Environmentally-efficient approaches to oil and gas producing sites
}

\author{
Mykhailo Liakh ${ }^{1}$, Teodoziia Yatsyshyn ${ }^{1 *}$, Svitlana Gavryliv ${ }^{1}$, Yuriy Gavryliv ${ }^{1}$, Lesia Shkitsa $^{1}$, Katarina Monkova ${ }^{2}$, \\ Peter Pavol Monka ${ }^{2}$, and Vasyl-Danylo Liakh ${ }^{2}$ \\ ${ }^{1}$ Ivano-Frankivsk National Technical University of Oil and Gas, 15 Karpatska Str., Ivano-Frankivsk, Ukraine \\ ${ }^{2}$ Technical University of Kosice, Sturova 31, 080 01, Presov, Slovakia
}

\begin{abstract}
We have offered the investigations aimed at the design of eco-efficient technologies during oil and gas producing sites life cycle. The authors have conducted the analysis of conditions causing environmentally hazardous situations at oil and gas producing sites. We have established the necessity of quick maintenance of operation during emergencies that makes it possible to reduce material costs and environmental pollution. The increase of environmental safety in the process of winding up oil and gas wells emergencies that took place as a result of catching drilling string or some other pipe is crucial. We have analyzed different ways and various structural designs of the devices for pipe unscrewing from caught strings. We have established the ways of negative environmental impact reduction in the winding up emergencies at operating as well at stack oil and gas rigs. The recommendations regarding the structural design of the device are given. The device design is patented and the prototype model of the device is designed and manufactured. The device functions as the transformer of clockwise drilling string rotation into anticlockwise rotation of fishing tools. We have highlighted the positive effects after the implementation of the given device. We have noted the importance of innovative technologies design as well as the importance of forming adequate response skills during emergencies when wellsites are being constructed. The technical solutions and recommendations we have introduced make it possible to prevent negative environmental impact and reduce resource flows at different stages of wellsite life cycle.
\end{abstract}

\section{Introduction}

The activities of oil and gas producing sites affect the environment, especially during some emergencies. The complexity of the issue lies in the fact that those oil and gas producing sites may be located close to protected or recreational areas [1]. Alongside with this negative effects may last for a long time and be dangerous to the environment [2], which calls for the search of innovative technical solutions, as well as alternative energy sources development. [3, 2] When industrial objects function in their normal mode it has a set of consequences: sickness rate increase, disturbance of natural environment functioning, resource capacity influence. There is also the economic constituent of the given issue $[4,5]$

\section{Analysis of previous publications}

The environment within the boundaries of oil and gas producing sites is intensively affected. Saksonov M.N. and others point out the environmental changes in the process of man-caused impact of oil and gas extraction [6] The most dangerous are the emergency situations that are the most unpredictable ones in terms of economic and environmental consequences $[7,8]$.
There is a set of conceptual approaches for maintaining environmentally safe production process at oil and gas producing sites $[9,10,11]$. The important measures that make it possible to prevent environmental pollution and to cut the material costs - are modernizing equipment [2, 12, 13]. Environmental aspect of modernizing equipment includes cutting expenditure resources during equipment manufacturing as well as during man-caused operations with the use of this equipment.

The investigations aimed at the increase of equipment operation responding for emergency drillstring jamming (e.g. pumping compressor, casing) in the wells are topical, because the removal of emergency situations demands unscrewing the pipes from the jammed part of the string, which is accompanied by economic losses, namely material and power ones. The removal time is also influences economic losses and environmental safety. If the wellsite is abandoned or put out of commission it is also necessary to unscrew the pipes. This calls for the necessity to develop environmentally efficient methods of prompt emergencies removal.

\footnotetext{
* Corresponding author: t.yatsyshyn@nung.edu.ua
} 


\section{The research results}

\subsection{The triggering events of environmentally hazardous situations at oil and gas producing sites}

Emergencies that take place at oil and gas complex, namely at wellsite are the cause of a set of environmental issues. These issues that are typical to oil and gas complex have been investigated in academic papers $[14,15,16$, 17].

Technological processes of oil and gas extraction are characterized by multicomponent structure of working environment (drilling fluids, extracted fluids and other technological fluids), that may contain toxic components and be flammable. These factors when summed up, pose a certain threat for the staff and contiguous territories with their inhabitants. One of the high risk-bearing factors is also the high level of technological equipment wearing. The processes that take place in this equipment cause its intensive degradation in long-term operation conditions and at presence of aggressive media that in their turn increase the environmental risks during oil and gas extraction. Equipment wearing is a serious risk factor that makes it difficult to solve environmental issues at oil and gas extraction complex.

In oil and gas extraction industry apart from specified and accounted pollution sources there may emerge unpredictable emergency conditions resulting in substantial costs of resources for primary operation conditions restoration, environmental pollution is noted and hazard to staff's health arises [18, 19, 20]. Different stages of oil and gas industry life cycle fig. 1 affect the environmental impact of different levels of intensity and damage [21]. Thus, we my single out specified emissions, caused by provided technological processes. Environmental hazards estimation if the impacts alike at are described at different stages in academic papers [22, $23,24,25]$. The most important stage of environmental impact estimation is monitoring of different environments [26, 27, 28].

Modern geophysical investigation methods make it possible to collect information about equipment condition and wellsite geological profile which helps to evade significant environmentally hazardous consequences with occurrence of environmentally hazardous substances [29, 30]. The combination of methods for environmental monitoring and equipment condition makes it possible to reduce the risk of environmentally hazardous cases. But emergency conditions that may occur during operating conditions should be removed within the shortest possible time. Thus, taking into account all the factors mentioned, the aim of this article is to develop the effective tool for unscrewing pipes within a wellsite with increased operation reliability and enhanced technological possibilities. The main idea of innovative tool development is to reduce time costs for removing emergency conditions that makes it possible to increase environmental safety level of the wellsite construction process and oil and gas extraction.

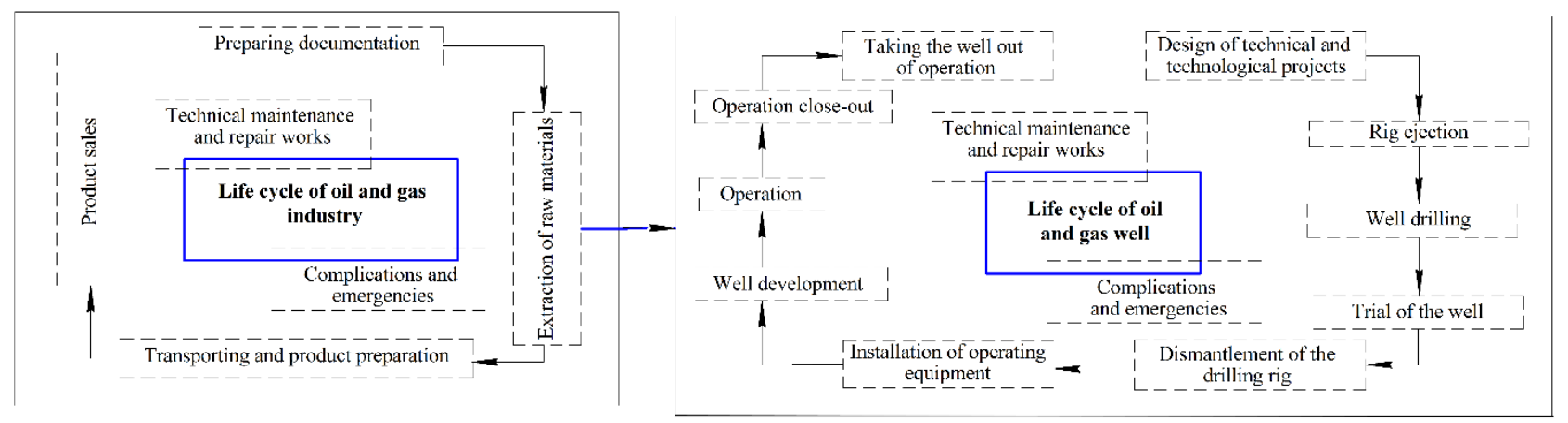

Fig. 1. The chart of life cycle of oil and gas well in the system of oil and gas extraction industry [21].

\subsection{The analysis of equipment constructions used for unscrewing pipes in the wellsite}

As we have already noted above, in emergency conditions it is crucial to select the technology that will make it possible to eliminate faults promptly and efficiently. Taking this into account we have analyzed the existing devices for unscrewing pipes in the wellsite.

We are aware about the device for unscrewing pipes in the wellsite [31], consisting of a case, upper (master) and lower (driven) pipes with pipeline thread for joining it to drilling strings and fishing tools respectively. This device also has an anchor knot (anchor) with fixing elements in the shape of elastic chambers and reverse gear in the shape of bevel gearbox. The master device also has the device for anchor knot actuation, consisting of throttling nut, screwed at the lower end of upper (master) shaft. The device sets the anchor knot going by means of feeding flushing liquid into fishing string, which at the cost of change of pressure in the throttling screw restores required pressure in the anchor knot and penetrates elastic chambers, broadening them for contact with the internal part of casing string.

The essential limitation in the use of this device is the low reliability of device fixture by flushing liquid pressure and also the use of elastic chambers as fixture elements as they may be corrupted when the device is lowered into the wellsite.

The next device for unscrewing pipes in the wellsite 
[32] is the one that has hollow cylindrical case with the pipe thread placed at its lower part. The hollow shaft with the screw is located at the upper part to be joined to the fishing string. The anchor knot (anchor) is also present with fixing telescopic parts and reversing gear in the shape of pull chain interacting with the rim, placed at the inner surface of hollow cylindrical case of the device. The driven device also has the mechanism for anchor knot activation which consists of throttling screw, placed at the lower end of hollow shaft. The device sets the anchor knot going by means of feeding flushing fluid into fishing strings that at the cost of change of pressure in the throttling screw causes pressure in the anchor knot case on fixture elements.

Among the drawbacks of this device are the following:

- reversing gear low performance index, that makes it impossible to create sufficient moment of force, necessary for screwing fishing instruments with further pipes unscrewing. It happens due to sufficient pull chain dragging against outer cylindrical case surface of anchor knot;

- technological complexity of the design of separate elements of the device, namely, the rim on the inner case surface.

There is also the device for unscrewing pipes in the wellsite [33] that has hollow cylindrical case with the left reducing coupling located at the lower part with the right coupling device located at the upper part of the device. The anchor knot with fixture elements is also present, the reversing gear in the shape of planet gear, consisting of master hollow shaft-gear and planet carrier placed so that it is possible to interact with shaft-gear and the rimmed surface, performed on inner cylindrical surface of the device's case. The shaft-gear device is placed at the roller bearing with the ability to rotate towards the case of the device and with the presence of anchor knot activation device.

The peculiarity of this device is the fact that the anchor knot fixture elements are designed in the shape of slips that have the ability by moving along pyramidal facets of the case of the device radially to interact by their working hard-alloy surface with the inner wall of the casing string, ensuring reliable fixture of the device.

Among the drawbacks of this device are the following:

- the use of slips in the anchor knot, placed at bearing slides such as "dovetail" significantly complicates the device configuration and decreases its operation reliability. It is caused by the penetration of abrasive particles that are abundant in the wellbore of that direction, which may result in jamming and, respectively - device nonoperation;

- the use of the wedge mechanism in the anchor knot significantly limits the range of radial slips advancement which does not ensure the possibility to use the driven device in casing strings of different diameter without the replacement of fixture elements.

In order to unscrew the stuck (jammed) drilling string two basic methods are used $[34,35]$. The first one - is the use of the string with double-sided screw, the second one presupposes the use of a special device that turns clockwise rotation of the given drilling string into anticlockwise rotation of the fishing tool (taper tap, collar socket, tubing catch, etc.) connected to the jammed part of the string.

The first method, the one that is using pipes with anticlockwise screw has the following drawbacks:

- the necessity to purchase or lease that kind of a string if it is operating at a different wellsite, or manufacturing the needed amount of them, which causes additional expenses;

- transportation expenses of a big number of pipes;

- the replacement of the existing string of pipes with that one with anticlockwise screw is a labor-consuming process;

- environmental pollution with exhaustion gases and petroleum products during transportation and double replacement of pipe strings;

- time-consuming preparatory works, associated with the expansion of storage space and storage of a big amount of pipes and increase of expenses, that has a negative effect on the environment.

Taking into account all the above-mentioned the given academic paper is mostly concentrated on the second method - the use of a special device for turning clockwise rotation of the given drilling string into anticlockwise rotation of the fishing tool. In our case it is obvious that the above-mentioned drawbacks are neutralized by using of anti-clockwise pipes.

\subsection{The design of innovative device construction for unscrewing pipes in the wellsite}

The purpose of design of a new efficient device is to create a device construction for unscrewing pipes in the wellsite with high performance output and improved technological possibilities, achieved at the expense of addition of anchor knot fixture elements of a specific shape to working surfaces, placing those fixture elements with the possibility of rotation towards the axe that are parallel to the axes of the device, and also the design of the device for anchor knot activation in the shape of spacious cam gear [36].

The given aim is achieved by the presence of a hollow cylindrical case in our device with the left pipe reducer placed at its lower part and the right pipe reducer placed at the upper part of the device. The anchor knot with fixture elements, reversing gear in the shape of planetary gear consisting of master hollow shaft-gear and carrier gear with satellites are also present.

The external working cylindrical surface of fixture elements is obtained by the motion of the generant in part of the Archimedean spiral and enabling fixture elements to rotate around the axes parallel to the axis of the device in order to change the external diameter of the device. It ensures bigger interaction area with internal surface of a casing string, which prevents its contact damages that may be the source of its further destruction. Besides that the offered construction of fixture elements makes it possible to use the designed device in casing strings of different diameters without the replacement of the very fixture elements.

The device for pipes unscrewing contains hollow cylindrical case 1 (fig. 2) that has geared surface 2 on its 
inner cylindrical surface and with left pipe adapter at its lower part 3.
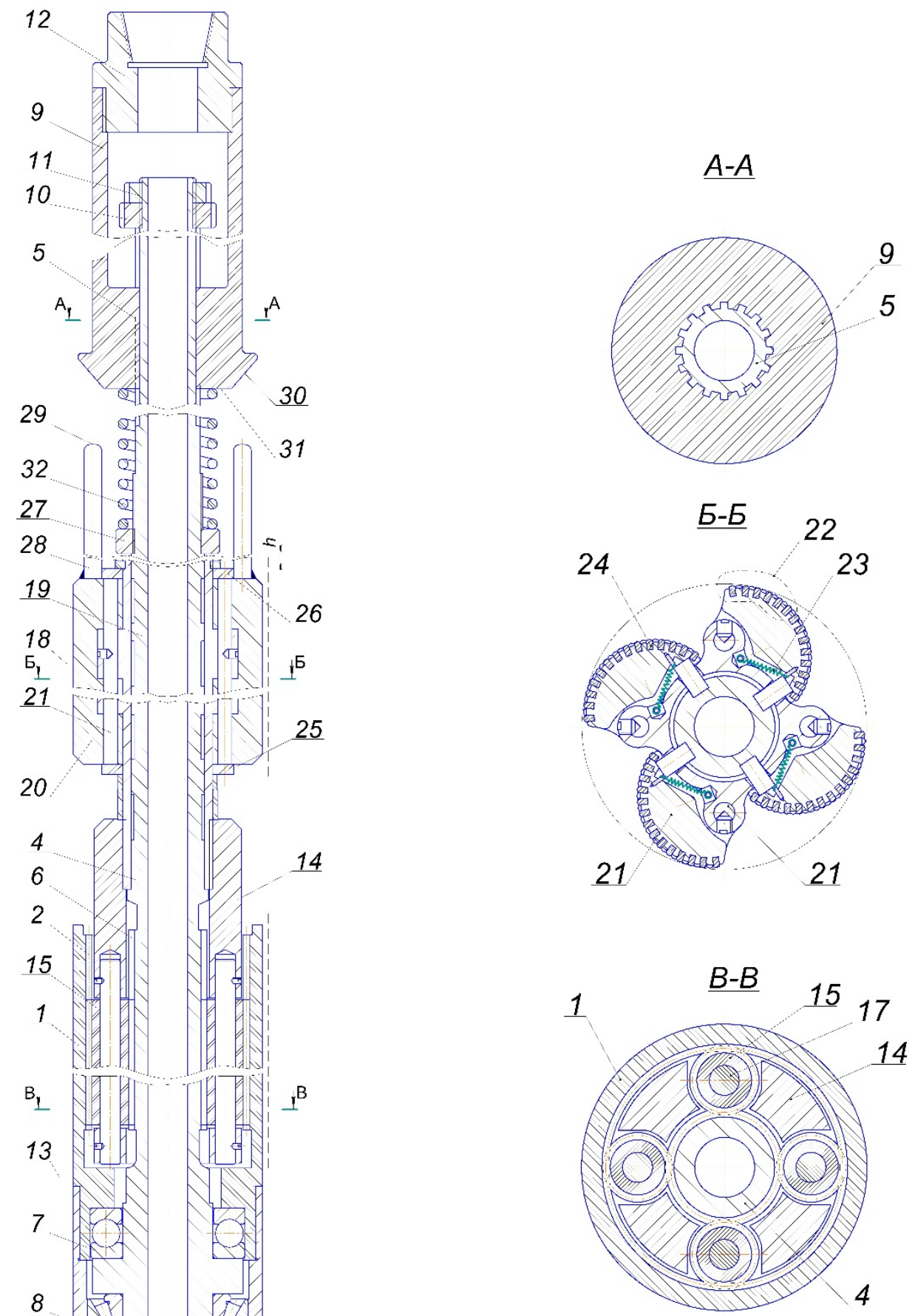

Fig. 2. The scheme of the device for unscrewing the captured column of pipes.

Inside the case 1 the hollow shaft-gear 4 is installed the upper end of which is designed in the shape of splined surface 5 , closer to the lower end of shaft-gear 4 there is geared surface 6 . The shaft-gear 4 is placed with the ability of rotation towards the case 1 of the device. With this purpose the rolling bearings 7 and 8 are placed at the lower part between them. On the upper part of the shaftgear 4 on splined surface 5 the spacing sleeve 9 is placed and it is able to perform limited axial movements towards shaft-gear 4 . The limitation of this movement is ensured by screw 10 , screwed at the geared end of shaft-gear 4 and fixed from unscrewing by locking nut 11. At the upper part of spacing sleeve 9 the right pipe adapter 12 is fixed with the help of screwed joint, adjoining it axis.

The device also has the reversing gear 13 in the shape of planetary gear, consisting of master hollow shaft-gear 
4, carrier gear 14 with satellites 15 placed with the possibility of interaction with external geared surface 6 of shaft-gear 4 and internal geared surface 2 , designed in the cylindrical hollow case 1 of the device. The satellites 15 are placed at the respectful hollows 16 of the carrier gear 14 on the axes 17.

The offered design of the device for pipes unscrewing also contains anchor knot 18 consisting of cylindrical case 19, immovably (e.g. by screw connection) fixed at the upper part of carrier gear 14 and placed with the possibility of rotation at shaft-gear 4 . The anchor knot 18 also has fixture elements 20 (ranging in number from 3 to 12) placed with the possibility of rotation around axes 21 , placed in case 19 parallel to shaft-gear 4 axis. The external working cylindrical surface 22 of fixture elements 20 is designed by the motion of the generant in part of the Archimedean spiral. Fixture elements 20 are manufactured from solid material like steel, processed by relevant thermochemical methods (cementing, boration, chromizing, etc.) and thermal (hardening+low dismissal) of treating. The working surface 22 is carved or armed by hard-alloyed insertion pieces 23 . The anchor knot 18 also has extension springs 24 (according to the number of fixture elements 20), the force of them being directed at rotation of fixture elements 20 towards $\mathrm{O}-\mathrm{O}$ axis of the device.

Apart from that the anchor knot 18 is provided by two spacers 25 and 26, placed at case 19 in order to fix axes 17 axially.
The anchor knot 18 is placed at shaft-gear 4 with the possibility of relative rotation and limited axial movement by the magnitude $\mathrm{h}$ that can be altered by adjustor nut 27 , screwed at screwed surface, performed at shaft-gear 4 under splined surface 5 .

The anchor knot drive of the patented device consists of abutting carrier gears 28 , immovably fixed at upper end faces of fixture elements 20 and designed in the shape of cylindrical shafts with spheric endings 29 . The lower part of spacing sleeve 9 consists of two surfaces: cutaway conus 30 and flat end surface 31 . The drive also contains the spring 32, placed between upper flat end surface of adjustor nut 27 and flat end surface 31 of spacing sleeve 9.

The sizes and mutual location of cutaway conus 30 and spheric endings 29 of carrier gears 28 ensure their interaction during the movement of spacing sleeve 9 (along splined surface 5 of shaft-gear 4 ) in the direction of spring 32 contraction.

Before the device installation it is necessary to conduct well logging that will make it possible to clearly define the place where the device should be installed [29, $30,37,38$ ] on the part of the pipe that is not damaged.

The device operates the following way. The offered device (fig. 2, 3) altogether with fishing tools: taper tap, drill pipe spear etc., attached to the lower pipe adapter 3, is lowered altogether with fishing string of right drilling pipes with the help of right upper pipe adapter 12 .
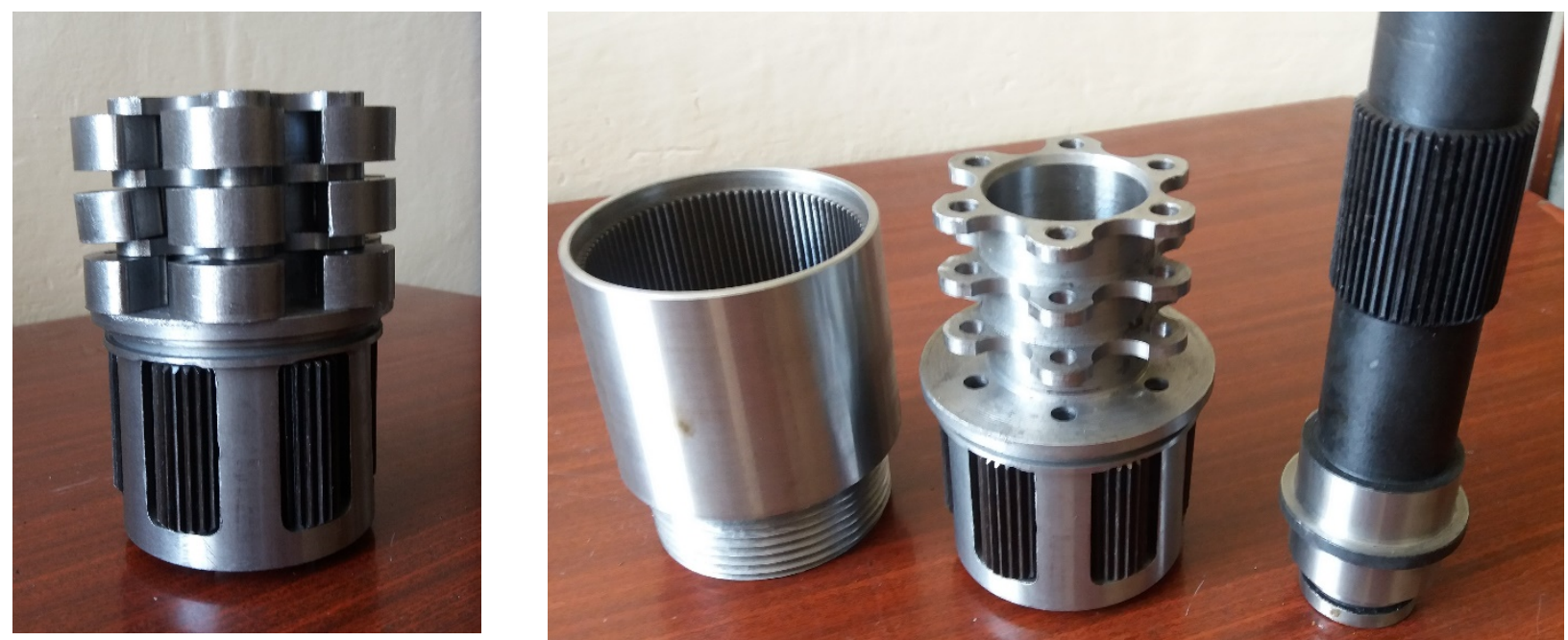

Fig. 3. Laboratory experimental model of a device for unscrewing a captured column of pipes.

This process is continued in the cased wellsite up to the lineup of the fishing tool with the upper end of the stuck string stern. Further lowering sets the upper pipe adapter 12 going altogether with spacing sleeve 9 along the splined surface 5 of shaft-gear 4, pressing string 32 by that. Conic surface 30 of spacing sleeve 9 starts interacting with spheric endings 29 of abutting carrier gears 28 resulting in the action of charge away from the $\mathrm{O}-\mathrm{O}$ axis of the device. As carrier gears 28 are immovably fixed at the upper faceplate of fixture elements 20 , the latter ones, resisting extension strings 24 , turn around their axes 21 towards case 19 of anchor knot 18, moving to contact external cylindrical surfaces 22 of fixture elements 20 with external wall of casing string.

Mutual axial location between spheric endings 29 of abutting carrier gears 28 and conic surface 30 of spacing sleeve 9 is adjusted by screw 10, screwed at screwed end of shaft-gear 4 and fixed from unscrewing by locking nut 11.

Spacers 25 and 26 are placed at the external cylindrical case surface 19 from the side of fixture elements edges 20 and mitigate axial movement 21 . Besides, spacers 25 and 26 do not let abrasive particles get into junction: the case holes 19 - axis 21 - fixture elements holes 20 , preventing jamming and device incapacitation. 
The anchor knot is fixed in the casing pipe by drilling string weight indicator.

Working surfaces 21 link with casing pipe wall. The reliability of this link is ensured by the design of fixture elements working surface by the motion of the generant in part of the Archimedean spiral and thread cutting fixture elements 20 on working surface 21 or reinforcement those surfaces by hard-alloyed insertion pieces 23. The link of fixture elements 20 with the external surface of casing pipe wall prevents anchor knot 18 from rotation in cased borehole.

The rotation is initiated by drilling string. As the anchor knot does not let carrier gear 14 rotate towards the $\mathrm{O}-\mathrm{O}$ axis of the device, planetary gear 13 is turned into common spindle reversing gear. Drilling string rotation through upper right pipe adapter 12, spacing sleeve 9, through splined surface 5 drags over to shaft-gear 4 and further through satellites 15, placed in the hollows 16 at axes 17 onto case 1 of the device. The latter, having the possibility of rotation towards shaft-gear 4 at rolling bearings 7 and 8 sets anticlockwise (reverse) rotation of the lower left pipe adapter 3 with the fishing tool.

After fishing tool is screwed into the emergency pipe body the unscrewing of the weakest thread in emergency drilling string is begun.

Axial movements that appear during fishing tool cutting-in and pipes unscrewing is ensured by axial movement (sliding) of satellites 15 along geared surfaces 2 and 6 respectively in case 1 of the device and at shaftgear 4 at the expense of spacing gap $\mathrm{h}$ between upper part of anchor knot 18 and lower edged surface of adjustor nut 27. Depending on fishing tool schedule and unscrewed pipes thread this spacing gap is adjusted by means of according tightening adjustor nut 27 .

After the weakest screwed joint assembly is unscrewed which is noted by drilling string weight indicator, the rotation of the fishing string is stopped and it starts being lifted. The impact of spring 32, placed between adjustor nut 27 and flat end surface 31 of spacing sleeve 9 , sets the spacing sleeve 9 going towards shaftgear 4. Alongside with that as a result of upward axial movement of conic surface 30 , the thrust force on spheric endings 29 of carrier gears 28 is reduced - fixture elements 20 under the impact of springs 24 reset, unlocking the device from casing string. The device with the unscrewed pipe or several pipes is lifted from the wellbore.

\section{Conclusions}

1. It is often the case with oil and gas production industry when emergency situations associated with catching (wedging up) drilling string or pumping-compressor pipes. And the number of these occasion call for the pipes unscrewing from the caught pipe.

2. The most popular way of unscrewing pipes from the caught pipe is the use of pipes with anticlockwise screw. This way is labor-consuming, power-consuming and causes environmental pollution.

3. The use of the way mentioned in clause 2 of the conclusion causes extra pollution to the environment by transportation means delivering and taking away big amounts of tools with anticlockwise screw and sustainable operation of drilling rig engines when the available pipes with clockwise screw are replaced by the ones with anticlockwise screw, and when the operation is completed, the reverse replacement takes place. The total length of pipes with anticlockwise screw is equal to the length of the wellbore and may comprise from $1000 \mathrm{~m}$ up to $6000 \mathrm{~m}$ and more.

4. The offered construction of the device that functions as a transformer of rotation direction is lowered into the wellbore with the aid of existing pipes with clockwise screw after which there is no necessity to use pipes with anticlockwise screw. It reduces the time of preparatory works needed to remove the emergency and respectively the environmental impact is shortened.

5 . The cost of the offered device is next lower order than with the use of pipes with anticlockwise screw.

6. In addition, in order to prevent environmentally hazardous situations oil and gas production sites should employ highly qualified and certified staff. This approach will reduce the impact of human factor as the reason of emergency situations by forming adequate response skills during emergencies when wellbores are being constructed. [39, 40, 41]. Specialists should be trained with the use of modern educational technologies that will make it possible to imitate real life conditions and get practical experience of proper response to incidents in the workplace [42].

\section{References}

1. N. Pobihun, Y. Korobeinykova, O. Pobihun, I. Iuras, Ecological and monitoring studies of oil production territories and possibility of their use in recreation, in Proceedings of the XIII International Scientific Conference "Monitoring of Geological Processes and Ecological Condition of the Environment”, vol. 2019, pp. 1-5. (2019). doi:10.3997/22144609.201903183

2. L. Shkitsa, T. Yatsyshyn, M. Lyakh, O. Sydorenko, Innovative approaches to the formation of environmental safety at the objects of oil and gas production. IOP Conf. Ser.: Mater. Sci. Eng. 749, 012009 (2020). doi:10.1088/1757899X/749/1/012009

3. O.M. Mandryk, N.R. Moskalchuk, L.M. Arkhypova, M.M. Pryhodko, O.V. Pobigun, Research quantitative indicators of the potential of solar energy in the Carpathian region of Ukraine. IOP Conf. Ser.: Mater. Sci. Eng. 749, 012033 (2020). doi:10.1088/1757-899X/749/1/012033O.M.

4. O. Savko, I. Melnychuk, I. Hobyr, N. Havadzyn, Evaluation of the environmental taxation effectiveness in the field of oil and gas production. Procedia Environ. Sci. Eng. Manag. 6(4), 607-617 (2019). http://www.procediaesem.eu/pdf/issues/2019/no4/69_Savko_19.pdf.

Accessed 30 Nov 2020 
5. I.B. Gobyr, Features of environmental taxation of oil and gas companies: practice of foreign countries. Eastern Europe: Economy, Business and Management. Economics of nature management and environmental protection 3(08) (2017). https://chmnu.edu.ua/wpcontent/uploads/2019/07/Gobir-I.-B..pdf. Accessed 30 Nov 2020

6. M.N. Saksonov, A.D. Abalakov, L.V. Danko, O.A. Barkhatova, etc., Ecological monitoring of the oil and gas industry. Physic-chemical and biological methods: textbook. allowance (Irkutsk University, Irkutsk, 2005), p.114

7. A.F. Atnabaev, R.N. Bakhtizin, S.V. Pavlov, G.M. Saifutdinova, Assessment of the consequences of emergency oil spills on main oil pipelines. Oil and gas business 1(4), 239-242 (2006)

8. Vladimirov V.A., Dubnov P.Yu. Emergency and other unauthorized oil spills. Civil protection strategy: problems and research 1 (2013). https://cyberleninka.ru/article/n/avariynye-i-drugienesanktsionirovannye-razlivy-nefti. Accessed 30 Nov 2020

9. E.M. Bakulin, M.M. Yavorsky, Svitlitsky V.M. etc. The concept of the environmental management system at the facilities of SC "Ukrgazvydobuvannya" in accordance with the requirements of ISO 14000 standards. Oil and gas energy. All-Ukrainian scientific and technical journal 1(2) 5-11 (2007)

10. C.B. Berzina Environmental management systems. Reference guide for the implementation of international standards series ISO 14000 (Aiva Plus Ltd, Kyiv, 2009), p. 62

11. S.V. Berzina, et al., Environmental management systems: current trends and international standards (Institute of Environmental Management and Sustainable Environmental Management, 2017). p. 134

12. I.A. Galanina, E.A. Urazova, Ecological modernization of the oil and gas complex. Issues of economics and management in industry complexes $\mathrm{p}$. 460 - 463.

13. L. Skitsa, T. Yatsyshyn, M. Liakh, O. Sydorenko, Ways to improve safety of a pumping-circulatory system of a drilling rig. Mining of Mineral Deposits 12(3), 71-79 (2018). doi:10.15407/mining12.03.071

14. A. Brandt, M. Masnadi, K. Than, Climate impacts of super-giant oilfields go up with age, Stanford scientists say (2017). https://news.stanford.edu/ 2017/07/17/climate-impacts-super-giant-oilfieldsgo-age/. Accessed 30 Nov 2020

15. A. Clark, R. Verity, S. Wheeler, R. Landau, Safety and environmental management in the oil and gas industry. A new model to enable line performance. Booz \& Company (2013). https://www.strategyand. pwc.com/media/file/Strategyand_Safety-andEnvironmental-Management-in-the-Oil-and-GasIndustry.pdf. Accessed 30 Nov 2020
16. R. Ellis, R.S. Adams, Contamination of Soils by Petroleum Hydrocarbons. Advances in Agronomy 13, 197-216 (1961)

17. A. Litovitz, A. Curtright, S. Abramzon, et al., Estimation of Regional Air-Quality Damages From Marcellus Shale Natural Gas Extraction in Pennsylvania. Environmental Research Letters 1(8), 8 (2013)

18. T. Yatsyshyn, L. Shkitsa, O. Popov, M. Liakh, Development of mathematical models of gas leakage and its propagation in atmospheric air at an emergency gas well gushing. Eastern-European Journal of Enterprise Technologies 5/10(101), (4959) 2019. doi:10.15587/1729-4061.2019.179097

19. Anne C.Epstein, Chapter Five - The Human Health Implications of Oil and Natural Gas Development. Advances in Chemical Pollution, Environmental Management and Protection 1, 113-145 (2017)

20. E. Broni-Bediako, R. Amorin, Effects of Drilling Fluid Exposure to Oil and Gas Workers Presented with Major Areas of Exposure and Exposure Indicators. Research Journal of Applied Sciences, Engineering and Technology 2(8), 710-719 (2010)

21. L. Shkitsa, T. Yatsyshyn, M. Liakh, et al., Innovative development of resourse-saving technologies for mining. Multi-authored monograph (Publishing House "St.Ivan Rilski”, Sofia, 2018), p. 439

22. A.O. Zaporozhets, Research of the Process of Fuel Combustion in Boilers, in Studies in Systems, Decision and Control, vol. 287 (Springer, Cham, 2020), pp. 35-60. doi:10.1007/978-3-030-46299-4_2

23. A.O. Zaporozhets, Methods and Means for the Control of the Fuel Combustion, in Studies in Systems, Decision and Control, vol. 287 (Springer, Cham, 2020), pp. 1-33. doi:10.1007/978-3-03046299-4_1

24. T. Yatsyshyn, Y. Mykhailiuk, M. Liakh, I. Mykhailiuk, V. Savyk, I. Dobrovolsky, Establishing the dependence of pollutant concentration on operational conditions at facilities of an oil and gas complex. Eastern-European Journal of Enterprise Technologies 2/10(92), 56-63 (2018). doi:10.15587/1729-4061.2018.126624

25. A.P. Khaustov, M.M. Redina, Chrezvychaynyye situatsii i ekologicheskaya bezopasnost' v neftegazovom komplekse http://docs.cntd.ru/document/ 499075302. Accessed 30 Nov 2020

26. A. Zaporozhets, V. Babak, V. Isaienko, K. Babikova, Analysis of the Air Pollution Monitoring System in Ukraine, in Studies in Systems, Decision and Control, vol. 298, ed. by V. Babak, V. Isaienko, A. Zaporozhets (Springer, Cham, 2020), pp. 85-110. doi:10.1007/978-3-030-48583-2_6

27. A. Zaporozhets, Overview of Quadrocopters for Energy and Ecological Monitoring, in Studies in Systems, Decision and Control, vol. 298, ed. by V. Babak, V. Isaienko, A. Zaporozhets (Springer, Cham, 2020), pp. 15-36. doi:10.1007/978-3-030-48583-2_2 
28. A. Iatsyshyn, A. Iatsyshyn, V. Kovach, I. Zinovieva, V. Artemchuk, O. Popov, O. Cholyshkina, O. Radchenko, O. Radchenko, A. Turevych, Application of Open and Specialized Geoinformation Systems for Computer Modelling Studying by Students and PhD Students. CEUR Workshop Proceedings 2732, 893-908 (2020), http://ceurws.org/Vol-2732/20200893.pdf. Accessed 25 Nov 2020

29. M.L. Myrontsov, Electrometry effective inverse problem solving method, in Proceedings of the 19th International Conference Geoinformatics Theoretical and Applied Aspects 2020, vol. 2020, pp. 1-5. (2020). doi:10.3997/2214-4609.2020geo090

30. M.L. Myrontsov, Lateral logging sounding and lateral logging complex effective inverse problem solving method, in Proceedings of the 19th International Conference Geoinformatics Theoretical and Applied Aspects 2020, vol. 2020, pp. 1-5. (2020). doi:10.3997/2214-4609.2020geo092

31. Author's certificate of the USSR № 1146411. Device for opening pipes in a well. Publ. March 23, 1985 Bull. № 11.

32. Author's certificate of the USSR № 1559104. Device for turning pipes in the well. Publ. 04/23/1990 Bull. № 15 .

33. Patent № 45428. Device for unscrewing pipes in a well. Publ. 15.04.2002 Bull. № 4 .

34. K.G. Levchuk, V.M. Moysishin, V.V. Rys, I.M. Gural, Mechanical methods of releasing the captured drilling tool (review). Prykarpatsky Bulletin of NTSh 2(38), 196-235 (2017)

35. V.I. Sklyanov, Substantiation of parameters of new technical means for increase of efficiency of highspeed diamond drilling of deep geological prospecting wells, Dissertation, Ros.gos.geol.razved. u-nt, Moscow, 2007

36. Utility model patent № 144078. Device for unscrewing pipes in a well. Publ. 08/25/2020 Bull. № 16.

37. M.L. Myrontsov, The method to research equivalent solutions zones for inverse problem of well logging electrometry, in Proceedings of the XIII International Scientific Conference "Monitoring of Geological Processes and Ecological Condition of the Environment", vol. 2019, pp. 1-5. (2019). doi:10.3997/2214-4609.201903217

38. M.L. Myrontsov, The method to solve the inverse problem of lateral logging sounding and lateral logging, in Proceedings of the XIII International Scientific Conference "Monitoring of Geological Processes and Ecological Condition of the Environment", vol. 2019, pp. 1-5. (2019). doi:10.3997/2214-4609.201903244

39. S. Kis, L. Mosora, Y. Mosora, O. Yatsiuk, G. Malynovska, S. Pobihun, Personnel Certification as a Necessary Condition for Enterprise' Staff Development, Management Systems in Production
Engineering 28(2), 121-126 (2020). doi:10.2478/mspe-2020-0018

40. A. Iatsyshyn, A. Iatsyshyn, V. Artemchuk, I. Kameneva, V. Kovach, O. Popov, Software tools for tasks of sustainable development of environmental problems: peculiarities of programming and implementation in the specialists' preparation. E3S Web Conf. 166, $01001 \quad$ (2020). doi:10.1051/e3sconf/202016601001

41. V. Gurieiev, Yu. Kutsan, A. Iatsyshyn, A. Iatsyshyn, V. Kovach, E. Lysenko, V. Artemchuk, O. Popov, Simulating Systems for Advanced Training and Professional Development of Energy Specialists in Power Sector. CEUR Workshop Proceedings 2732, 693-708 (2020). http://ceur-ws.org/Vol2732/20200693.pdf. Accessed 25 Nov 2020

42. A.V. Iatsyshyn, V.O. Kovach, V.O. Lyubchak, Y.O. Zuban, A.G. Piven, O.M. Sokolyuk, A.V. Iatsyshyn, O.O. Popov, V.O. Artemchuk, M.P. Shyshkina, Application of augmented reality technologies for education projects preparation. CEUR Workshop Proceedings 2643, 134-160 (2020). http://ceurws.org/Vol-2643/paper07.pdf. Accessed 25 Nov 2020 